\title{
Inducible nitric oxide synthase in T cells regulates $T$ cell death and immune memory
}

\author{
Monika Vig,, ${ }^{1}$ Smita Srivastava, ${ }^{1}$ Usha Kandpal, ${ }^{1}$ Hadassah Sade, ${ }^{2}$ Virginia Lewis, ${ }^{3}$ Apurva Sarin, ${ }^{2}$ \\ Anna George," Vineeta Bal, ${ }^{1}$ Jeannine M. Durdik, ${ }^{3}$ and Satyajit Rath1
}

${ }^{1}$ National Institute of Immunology, New Delhi, India. ${ }^{2}$ National Centre for Biological Sciences, Bangalore, India. ${ }^{3}$ Department of Biological Sciences, University of Arkansas, Fayetteville, Arkansas, USA.

\begin{abstract}
The progeny of Tlymphocytes responding to immunization mostly die rapidly, leaving a few long-lived survivors functioning as immune memory. Thus, control of this choice of death versus survival is critical for immune memory. There are indications that reactive radicals may be involved in this death pathway. We now show that, in mice lacking inducible nitric oxide synthase (iNOS), higher frequencies of both CD4 and CD8 memory T cells persist in response to immunization, even when $\mathrm{iNOS}^{+/+}$APCs are used for immunization. Postactivation $\mathrm{T}$ cell death by neglect is reduced in iNOS $-/-\mathrm{T}$ cells, and levels of the antiapoptotic proteins $\mathrm{Bcl}-2$ and $\mathrm{Bcl}-\mathrm{xL}$ are increased. Inhibitors of the iNOS-peroxynitrite pathway also enhance memory responses and block postactivation death by neglect in both mouse and human $\mathrm{T}$ cells. However, early primary immune responses are not enhanced, which suggests that altered survival, rather than enhanced activation, is responsible for the persistent immunity observed. Thus, in primary immune responses, iNOS in activated T cells autocrinely controls their susceptibility to death by neglect to determine the level of persisting CD4 and CD8 T cell memory, and modulation of this pathway can enhance the persistence of immune memory in response to vaccination.
\end{abstract}

\section{Introduction}

In response to infection or immunization, the mammalian $\mathrm{T}$ cell immune response generates large numbers of proliferating progeny from the antigen-specific clonal precursors in the preimmune repertoire (1-3). A large proportion of these T cells differentiate to an effector phenotype capable of making high levels of secondary cytokines rapidly, and most die relatively soon during the immune response (4-6). Of the remaining antigen-specific T cells, some survive as long-lived memory cells capable of mounting a proliferative response upon challenge. It appears that $\mathrm{T}$ cell memory, whether of the effector or the central kind $(7,8)$, may be generated via a common pathway (9), which is modeled as either a branching or a sequential relationship between effector and memory cell generation $(10,11)$.

While loss of responding $T$ cells in postactivation death (PAD) by apoptosis $(6,12)$ is clearly a major factor regulating memory, the precise PAD pathways involved in various situations are not well understood. Death receptor-induced caspase-activating apoptotic pathways are most notably mediated by TNF/TNF receptor-family interactions such as CD95-CD95L for T cells undergoing activation-induced cell death $(\mathrm{AICD})(6,13,14)$. Apoptosis of T cells, particularly those undergoing apoptosis due to trophic signal withdrawal (trophic signal withdrawal death; TSWD), may also be mediated by mitochondrial death pathways, both caspase-mediated and caspase-independent (15-19). Prolonged T cell stimulation, as seen in autoreactive T cells undergoing deletion, is necessary for AICD (6,

\footnotetext{
Nonstandard abbreviations used: activation-induced cell death (AICD); aminoguanidine (AG); glutathione-monoethyl ester (GSH-mee); inducible nitric oxide synthase (iNOS); maleylated ovalbumin (maleyl-OVA); Mn(III)tetrakis(4-benzoic acid)porphyrin (MnTBAP); $N^{\mathrm{G}}$-monomethyl-L-arginine (L-NMMA); postactivation death (PAD); reactive nitrogen intermediate (RNI); reactive oxygen species (ROS); signal transducer and activator of transcription-5 (STAT-5); T cell receptor (TCR); trophic signal withdrawal death (TSWD); ZVAD-fluoromethylketone (ZVAD-fmk) Conflict of interest: The authors have declared that no conflict of interest exists.

20). TSWD, usually invoked in T cell homeostasis (21), is prevented by overexpression of antiapoptotic members of the Bcl-2 family of proteins, which also enhances persistence of immune memory (22, 23); this implies that TSWD may be relevant for memory.

Reactive free radicals, both reactive oxygen species (ROS) and reactive nitrogen intermediates (RNIs), as well as their products, such as peroxynitrite, are major triggers inducing apoptosis via mitochondria $(24,25)$. Inhibitors of some of these pathways inhibit $T$ cell death in a variety of situations $(19,25)$. Nitric oxide is produced by inducible nitric oxide synthase (iNOS) in a variety of cell types, although iNOS expression in T cells is controversial (26, 27). On this background, we have examined the role of RNIs in $T$ cell memory by both genetic and pharmacological means, and our data show that iNOS in T cells plays a major role in postactivation TSWD to regulate the persistence of $T$ cell memory.

\section{Results}

Higher frequencies of memory T cells persist in the absence of $i N O S$. WT or iNOS $-1-$ mice were immunized with a protein immunogen, maleylated ovalbumin (maleyl-OVA), on alum. Six weeks after immunization, the $\mathrm{T}$ cell-proliferative responses recalled in culture with maleyl-OVA were greater in the $\mathrm{iNOS}^{-/}$mice than in WT counterparts (Figure 1A). Limiting-dilution analysis assays of this response showed that the clonal frequency of maleyl-OVA-specific T cells was greater in iNOS $-/$ mice than in WT mice (Figure 1B). However, the extent of proliferation in maleyl-OVA-reactive wells at clonal frequency, indicating the clonal burst size of maleyl-OVA-specific $\mathrm{T}$ cells, did not differ between WT and $\mathrm{iNOS}^{-/-}$mice (Figure 1C).

To characterize the memory $\mathrm{T}$ cell response in iNOS $-/$ mice further for both CD4 and CD8 T cells, mice were immunized with two peptides from OVA, one MHC class I-restricted (OVA1; ref. 28) and the other MHC class II-restricted (OVA2; ref. 29), in CFA. Control mice were immunized with CFA alone. Six weeks later, T cells restimulated with peptides in culture were analyzed flow-cytometrically for CD44, intracellular IFN- $\gamma$, and CD4 (for cultures stimulat- 

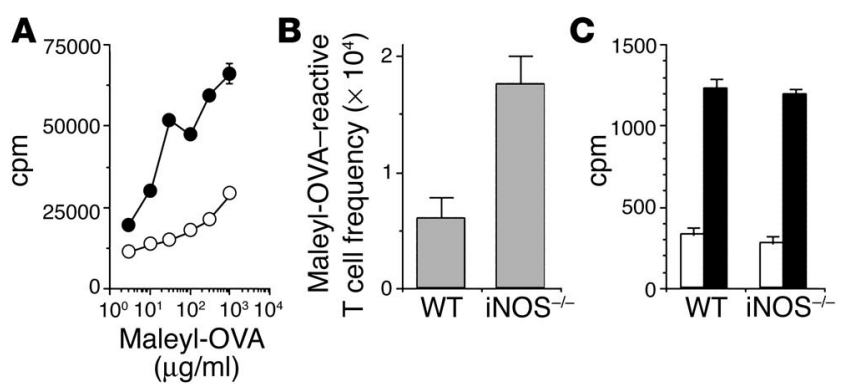

ed with the OVA2 peptide) or CD8 (for cultures stimulated with the OVA1 peptide). Neither the OVA2 nor the OVA1 peptide triggered any significant IFN- $\gamma$ expression in CD4 or CD8 T cells from control mice (Figure 2, A and B). Small but significant frequencies of IFN- $\gamma$ expression could be detected in CD44hi CD4 and CD8 T cells from peptide-immune WT mice as expected, and these were substantially higher in cultures from iNOS $/ /$ mice (Figure 2, A-D).

If the persistence of memory $\mathrm{T}$ cells is enhanced in $\mathrm{iNOS}^{-/-}$mice, their peripheral lymphoid organs would be expected to reflect this. We therefore examined the cellularity of inguinal lymph nodes from normal nonimmunized WT and $\mathrm{iNOS}^{-/-}$mice, as well as the frequency of CD4 and CD8 T cells showing cell-surface marker phenotypes characteristic of effector/memory cells. Lymph nodes from iNOS ${ }^{-/}$mice showed greater cellularity and increased numbers of both CD4 and CD8 T cells (Figure 3A). Further, the proportions of both CD4 and CD8 T cells showing CD44hi or CD62L $\mathrm{L}^{\text {lo }}$ phenotypes found on non-naive $T$ cells were significantly higher in $\mathrm{iNOS}^{-/-}$than in WT mice (Figure 3B).

Enhanced persistence of memory in iNOS ${ }^{-/-}$mice is due to the absence of iNOS in T cells. We next asked whether the observed enhancement of the persistence of immune memory depended on the absence of iNOS from T cells or from APCs. WT or iNOS-/- mice were immunized with MHC-mismatched APCs from iNOS ${ }^{+/+} \mathrm{BALB} / \mathrm{c}$ mice, and both $\mathrm{CD} 4$ and $\mathrm{CD} 8 \mathrm{~T}$ cell responses against the BALB/c MHC haplotype $\left(\mathrm{H}-2^{\mathrm{d}}\right)$ were measured 7 weeks later. For this, responder cells were labeled with CFSE prior to stimulation with BALB/c APCs in culture, and the frequency of CD4 or CD8 T cells undergoing proliferation as indicated by dilution of the fluorescein label was estimated by flow cytometric analysis. Far greater frequencies of both CD 4 and CD8 T cells from iNOS ${ }^{-/}$mice underwent proliferation, as indicated by CFSE dilution (Figure 4, A and B), than did cells from WT mice. However, the responding iNOS ${ }^{-/-}$cells had not gone through greater numbers of proliferation cycles on average as compared with the responding WT cells (Figure 4, A and B).

We extended these observations by transferring WT or iNOS - $^{-}$ splenic cells to Thy-1-congenic iNOS ${ }^{+/+}$B6.PL-Thy ${ }^{a} / \mathrm{Cy}$ mice, in

\section{Figure 2}

Higher frequencies of cytokine-secreting CD4 and CD8 memory $T$ cells in iNOS ${ }^{-1}$ mice. (A-D) T cell memory responses 6 weeks after immunization of WT or iNOS- ${ }^{--}$mice with OVA1 and OVA2 peptides (+ peptide) or with adjuvant alone (- peptide), by restimulation with (+) or without (-) either OVA2 (A) or OVA1 (B) peptide, followed by flow cytometric analysis of the CD4 (A) or CD8 (B) cells for expression of CD44 versus intracellular IFN- $\gamma$. The frequencies of IFN- $\gamma$-expressing CD4 (C) or CD8 (D) cells in groups of WT or iNOS ${ }^{--}$mice immunized with peptides (gray bars) or with adjuvant alone (white bars) are shown as mean \pm SE $(n=3)$.

\section{Figure 1}

Higher frequencies of proliferation-competent memory CD4 T cells in the absence of iNOS. T cell memory responses were measured 6 weeks after immunization with maleyl-OVA, as (A) bulk proliferative responses from WT (open circles) and iNOS ${ }^{-/-}$(filled circles) mice, (B) limiting-dilution analysis-based frequency, and (C) clonal burst size as measured by proliferation in wells scoring positive (black bars) or negative (white bars) at clonal frequencies.

which the donor WT or iNOS-/- C57BL/6 Thy-1.2 T cells can be distinguished from endogenous Thy-1.1 T cells. The recipient mice were immunized with maleyl-OVA in CFA so that both CD4 and CD8 responses could be generated and measured, since maleylOVA is efficiently presented for MHC class I-mediated activation of CD8 T cells (30). At 40 days after immunization, draining lymph node cells were stimulated with maleyl-OVA $(100 \mu \mathrm{g} / \mathrm{ml})$ for 24 hours, and the cells were stained for CD4/CD8, Thy-1.2, and intracellular IFN- $\gamma$. Antigen-specific CD4 and CD8 T cells of either WT or iNOS 1 - donor origin were thus enumerated flow-cytometrically in the appropriate recipient mice. There were significantly

$\mathbf{A}$

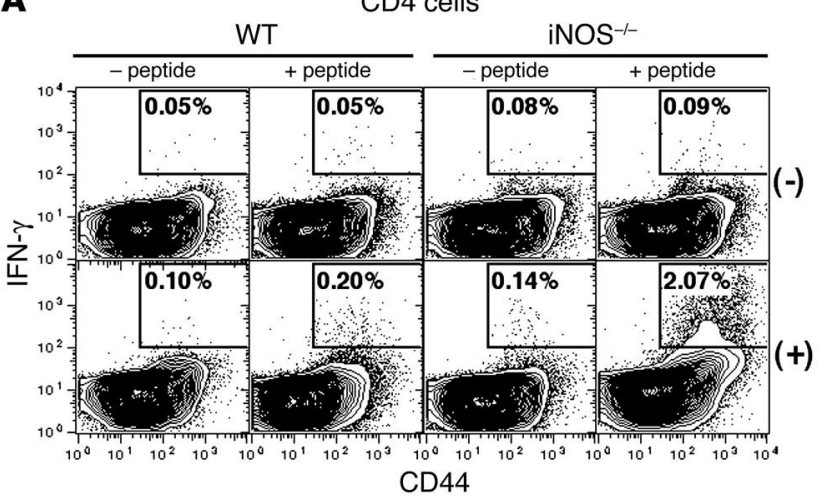

$\mathbf{B}$

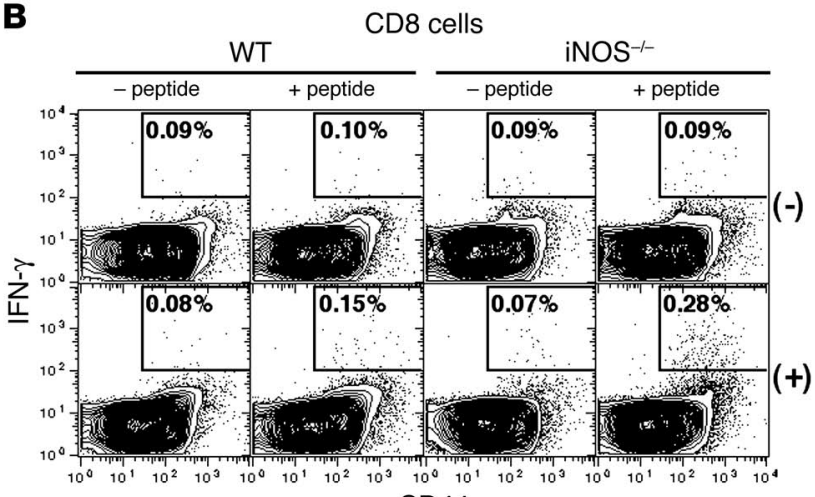

CD44

C

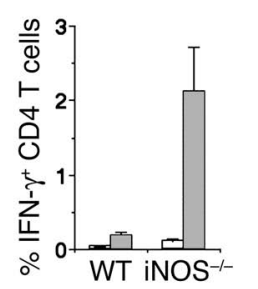

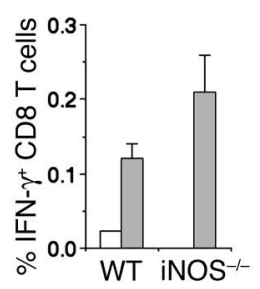


A

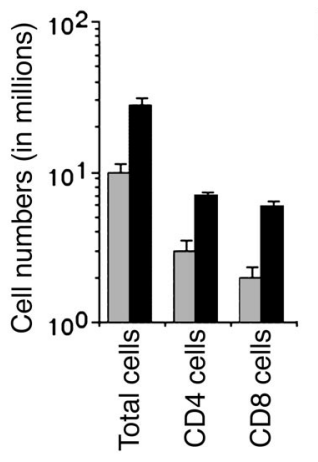

B

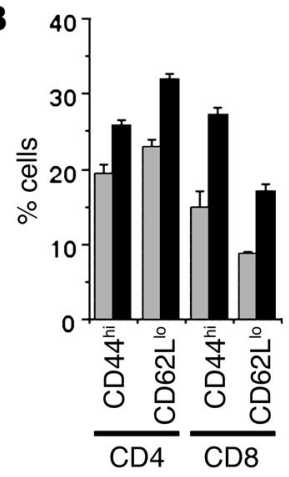

Figure 3

Higher numbers and frequencies of CD4 and CD8 memory-phenotype T cells in lymph nodes of iNOS ${ }^{-/}$mice. Inguinal lymph node cells from normal WT (gray bars) or iNOS ${ }^{--}$(black bars) mice were stained flow cytometrically for CD4 or CD8 and the activation markers CD44 and CD62L. (A) The numbers of total, CD4, and CD8 cells per lymph node and (B) the frequencies of secondary CD4 and CD8 T cells are shown as mean $\pm \operatorname{SE}(n=3)$.

higher frequencies of antigen-specific donor Thy-1.2 CD4 and $\mathrm{CD} 8$ cells persisting in recipients given iNOS-/- cells than in those given WT cells (Figure 4C).

Postactivation TSWD of CD4 and CD8 T cells is reduced in the absence of $i N O S$. We next confirmed that activated T cells from WT mice expressed iNOS protein. T cells from WT or iNOS ${ }^{-/}$mice were activated with anti-CD3 mAb and IL-2 for 4 days, and Western blot analysis was done for iNOS or for P38MAPK as a normalizing control. While activated T cells from WT mice expressed iNOS protein, iNOS $-1-$ cells did not (Figure 5A).

We tested in vitro whether activated T cells from iNOS ${ }^{-/-}$mice were protected from either AICD or TSWD. T cell blasts generated from WT, iNOS $-/$, or CD95-deficient B6.lpr mice were kept in medium devoid of IL-2 to induce TSWD (31), or restimulated with plate-bound anti-CD3 mAb and IL-2 to induce AICD (6). Death was detected by staining of the cells 12-48 hours later for CD4/ CD8 along with the DNA-binding dye Hoechst 33342 to determine proportions of cells with apoptotic nuclei by microscopy (31). CD4 and CD8 T cells from iNOS-/- mice showed substantially lower TSWD than WT or B6.lpr cells did (Figure 5, B and C). On the other hand, $\mathrm{T}$ cells from B6.lpr mice were substantially protected from AICD, while T cells from iNOS-/- mice showed little alteration in their susceptibility (Figure 5, D and E). We examined the possibility that iNOS ${ }^{-1-} \mathrm{T}$ cells survived better by continuing to make IL-2 by measuring IL-2 levels in culture supernatants from $\mathrm{T}$ cells undergoing TSWD at 12 and 24 hours, but no IL-2 was detectable from either WT or iNOS-- T cell cultures.

Peroxynitrite scavenging during mouse $T$ cell priming in vitro enhances persistence of primed $T$ cells and blocks T cell TSWD. We next looked at the effect of the pharmacological blockade of peroxynitrite on $\mathrm{T}$ cell memory and PAD. For this, we used an experimental system we have previously reported (32), in which T cells were immunized in vitro by priming with MHC-mismatched APCs from $\mathrm{iNOS}^{+/+} \mathrm{BALB} / \mathrm{c}$ mice, $\mathrm{H}-2^{\mathrm{d}}$-specific $\mathrm{T}$ cell-proliferative responses were measured in a restimulation assay against the stimulator APCs, and the enhancement of proliferative responses in primed versus unprimed responder cells was taken as a quantitative estimate of effective priming. APCs used in priming were

lightly fixed with paraformaldehyde, rendering them metabolically inactive but still capable of effective priming (33) (Figure $6 \mathrm{~A}$ ), in order to ensure that the effects of pharmacological agents added in priming cultures were mediated on the responder $\mathrm{T}$ cells directly. As expected, when iNOS $-1-$ responder cells were primed in culture in vitro, they yielded far better secondary proliferative responses than WT responders did (Figure 6A).

We used Mn(III)tetrakis(4-benzoic acid)porphyrin (MnTBAP) as a peroxynitrite scavenger (19). When MnTBAP was added to priming cultures of WT responder cells, it substantially enhanced the secondary response (Figure 6A). MnTBAP is also a mimic of catalase and superoxide dismutase, and it was necessary to examine whether its effect needed the presence of nitric oxide or was independent of it. We therefore added MnTBAP to priming cultures of iNOS $-/$ responder cells, and we found that it was completely ineffective in enhancing their secondary response any further (Fig 6A).

We also looked at the role of CD95-CD95L interactions in the enhancement of $\mathrm{T}$ cell memory in this assay. T cells from CD95deficient B6.lpr mice showed only as much enhancement of secondary responsiveness during allo-priming in vitro as WT cells did (Figure 6B), unlike cells from iNOS ${ }^{-/}$mice. Further, MnTBAP added during priming effectively enhanced the secondary responses of $\mathrm{T}$ cells from B6.lpr mice (Figure 6B).

We also tested the effects of pharmacological, rather than genetic, inhibition of iNOS activity in this system. When the iNOS inhibitor aminoguanidine (AG) was added to priming cultures of WT responder T cells and allo-APCs, it substantially enhanced the subsequent secondary response, as expected (Figure 6C).

We confirmed that MnTBAP as well as the iNOS inhibitors AG and $N^{\mathrm{G}}$-monomethyl-L-arginine (L-NMMA) protected WT T cells from postactivation TSWD in vitro. Anti-CD3-activated T cells from WT mice were kept in medium devoid of IL-2 for induction of TSWD, with or without MnTBAP, and death in CD4 and CD8 cells detected as described earlier. The presence of AG, L-NMMA,
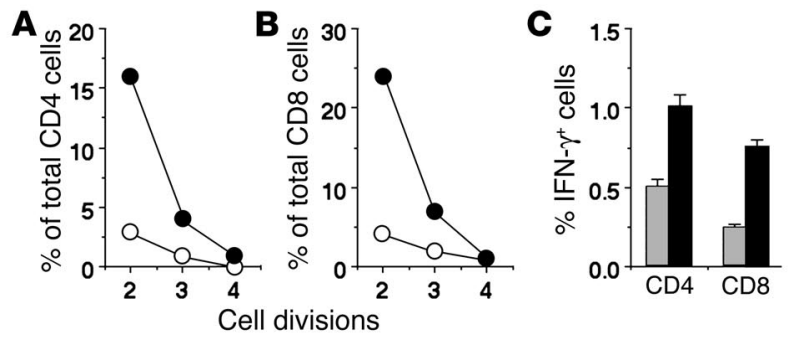

\section{Figure 4}

Absence of iNOS in T cells leads to enhanced persistence of immune memory. (A and B) Responses of allo-immunized WT or iNOS ${ }^{-/-} \mathrm{T}$ cells to BALB/c spleen APCs 7 weeks after immunization, measured by CFSE dilution 96 hours after in vitro restimulation with or without allo-stimulator APCs. The frequencies of CD4 (A) or CD8 (B) cells at each division are shown as mean \pm SE $(n=3)$ for groups of WT (open circles) or iNOS ${ }^{-/}$(filled circles) mice. (C) T cell memory responses in donor WT or iNOS ${ }^{--}$T cells 40 days after maleyl-OVA immunization of Thy-1-congenic recipients given either WT or iNOS ${ }^{-/-}$Thy-1.2 cells prior to immunization. Immune responses were scored by restimulation with maleyl-OVA followed by flow cytometric analysis of the donor Thy1.2 CD4 or CD8 cells for expression of intracellular IFN- $\gamma$. The frequencies of IFN- $\gamma$-expressing maleyl-OVA-specific CD4 or CD8 cells from either WT (gray bars) or iNOS $^{-1-}$ (black bars) donors in groups of Thy-1congenic recipient mice are shown as mean \pm SE $(n=5)$. 


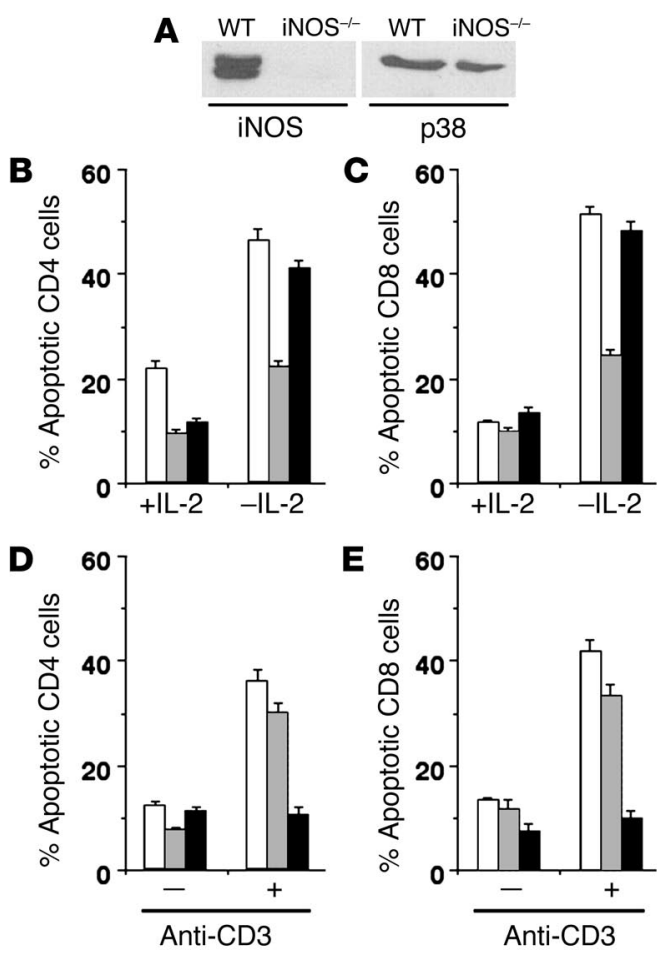

or MnTBAP substantially reduced the proportion of apoptotic cells in both CD4 and CD8 compartments (Figure 6, D-F).

We also confirmed that MnTBAP enhances physiologically relevant $\mathrm{T}$ cell memory in vivo, by immunizing mice with OVA on alum and treating them with MnTBAP or saline from day -2 to day +5 of immunization. The dosage of MnTBAP used $(3 \mathrm{mg} / \mathrm{kg})$ was in the dosage range reported to be efficacious in vivo in mice (1-5 $\mathrm{mg} / \mathrm{kg})(34,35)$. Six weeks later, when their T cell-proliferative responses to OVA were measured in vitro, it was clear that MnTBAP treatment for a short period of time early during the immune response had enhanced the $T$ cell memory generated (Figure $6 \mathrm{G}$ ). Further, when mice were treated with the iNOS inhibitor AG similarly from day -2 to day +5 of immunization with maleyl-OVA in

\section{Figure 6}

Mouse $T$ cells show enhanced memory and better survival following iNOS inhibition or peroxynitrite depletion. (A-C) Cells from WT (solid lines), iNOS ${ }^{-1-}$ (dashed lines, A), or B6.Ipr (dashed lines, B) mice were incubated alone (open circles) or primed with lightly fixed BALB/ c APCs in vitro without (filled circles) or with MnTBAP (filled squares) or AG (filled triangles), and restimulated with irradiated BALB/c spleen cells. (D) TSWD in T cell blasts from WT mice after 24 hours of culture in IL-2 (white bars), or without IL-2 in medium alone (black bars) or with AG (light gray bars) or L-NMMA (dark gray bars). Frequencies of apoptotic CD4 or CD8 cells are shown as mean \pm SE for triplicate cultures. (E and F) TSWD in T cell blasts from WT mice 12 hours after withdrawal of growth factors in the absence (white bars) or presence (gray bars) of MnTBAP. Frequencies of apoptotic CD4 (E) or CD8 (F) cells are shown as mean \pm SE for triplicate cultures. $(\mathbf{G})$ Mice were immunized with OVA and treated with saline (filled circles) or MnTBAP (filled squares) daily from day -2 to day +5 of immunization, and the proliferative memory response was measured after 6 weeks. $(\mathbf{H})$ Mice were immunized with maleyl-OVA and treated with saline (white bars) or AG (gray bars) daily from day -2 to day +5 of immunization, and the proliferative memory response was measured after 5 weeks.

\section{Figure 5}

Activated iNOS ${ }^{-/-}$T cells are protected from TSWD. (A) Western blot analysis for iNOS or p38MAPK proteins in T cell blasts from WT or iNOS $^{-/-}$mice. (B-E) Frequencies of apoptotic CD4 (B and D) and CD8 (C and E) T cells from WT (white bars), iNOS ${ }^{-1-}$ (gray bars), and B6.Ipr (black bars) mice undergoing TSWD 12 hours after withdrawal of signals (B and $\mathbf{C}$ ), or AICD at 48 hours (D and E), shown as mean \pm SE for triplicate cultures.

CFA, their T cell-proliferative responses to maleyl-OVA in vitro 5 weeks later were significantly more than those of mice receiving saline alone, suggesting that the short period of AG treatment had enhanced the T cell memory generated (Figure $6 \mathrm{H}$ ). The dosage of AG used $(100 \mathrm{mg} / \mathrm{kg})$ was also in the dosage range reported to be efficacious in mice $(30-300 \mathrm{mg} / \mathrm{kg})(36,37)$.

Absence of $i N O S$ or peroxynitrite leads to enhanced levels of the antiapoptotic proteins $\mathrm{Bcl}-2$ and $\mathrm{Bcl}-x \mathrm{~L}$ in activated $\mathrm{T}$ cells undergoing TSWD. In order to explore the mechanisms mediating the protection of activated T cells from TSWD, we examined the levels of expression of the major antiapoptotic members of the Bcl-2 family, Bcl-2 and Bcl-xL, by Western blot analysis in the activated iNOS $^{-/}$, WT, or MnTBAP-treated WT T cells cultured under various conditions. The results showed that, by 12 hours after IL-2 withdrawal, WT T cells ceased to show expression of either Bcl-2 or Bcl-xL, in contrast to cells maintained in the presence of IL-2 (Figure 7A). However, if the WT T cells were treated with MnTBAP, or if iNOS $^{-/-}$T cells were subjected to IL-2 withdrawal, substantial levels of Bcl-2 and Bcl-xL continued to be present (Figure 7A).
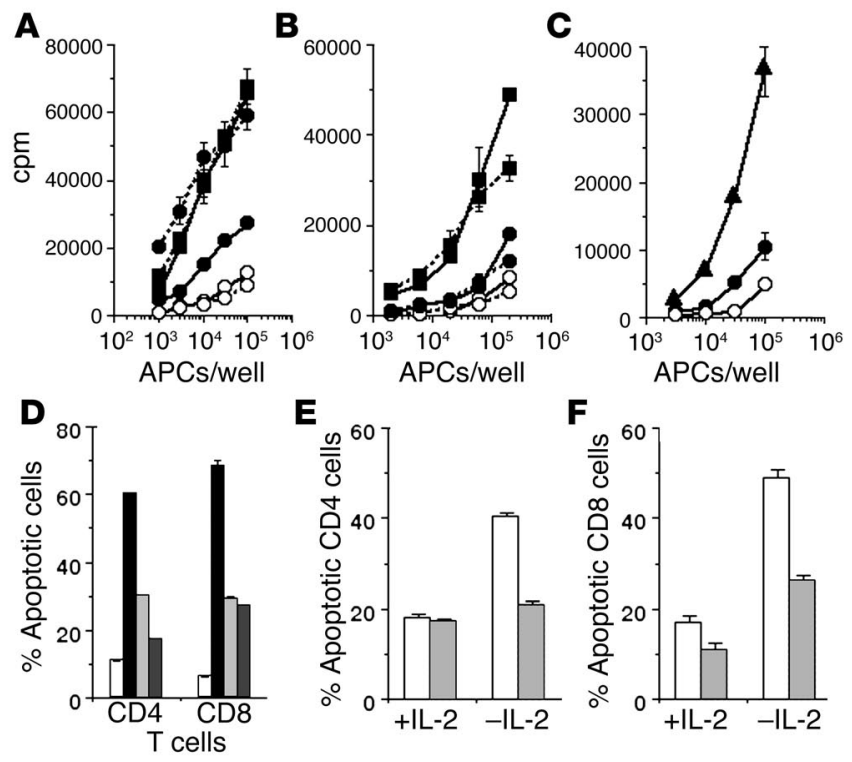

E
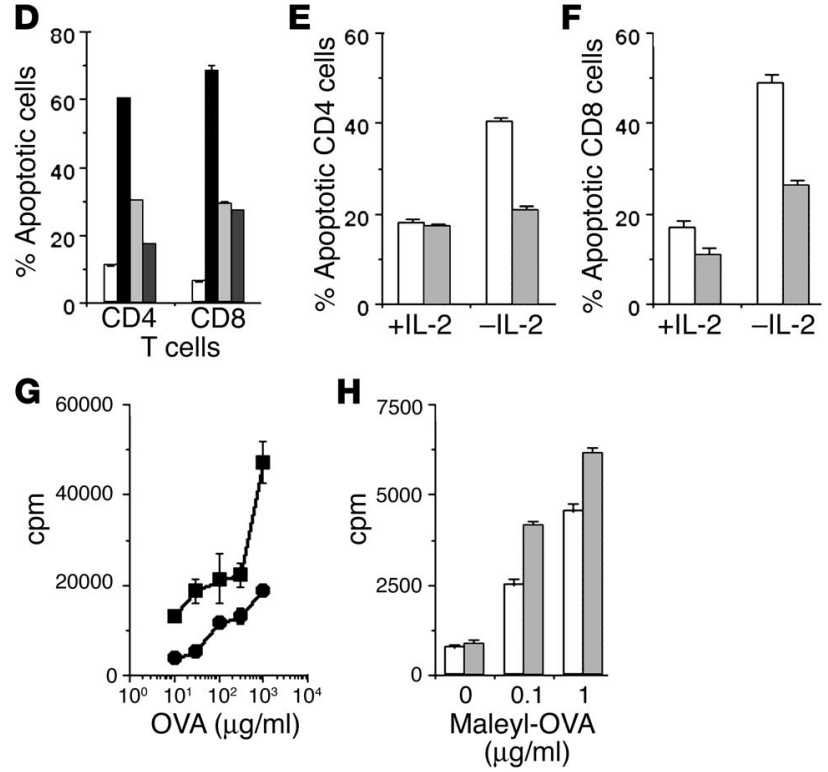
A

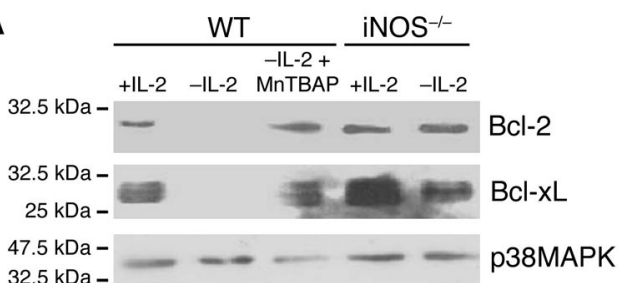

B

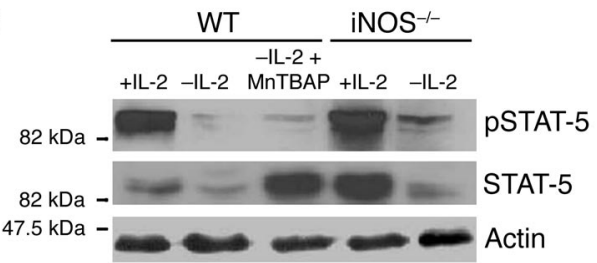

Figure 7

Regulation of antiapoptotic Bcl-2 protein family members by iNOS and peroxynitrite. (A) T cell blasts from WT or iNOS ${ }^{-1-}$ mice undergoing TSWD with or without MnTBAP, harvested 12 hours after IL-2 withdrawal and subjected to Western blot analysis for $\mathrm{Bcl}-2, \mathrm{Bcl}-\mathrm{xL}$, or p38MAPK as shown. (B) T cell blasts from WT or iNOS ${ }^{-1-}$ mice undergoing TSWD with or without MnTBAP, harvested 1 hour after IL-2 withdrawal and subjected to Western blot analysis for STAT-5, pSTAT-5, or actin as shown.

We next examined some of the upstream signals thought to be responsible for controlling the expression of these Bcl-2-family proteins. One major mediator of $\mathrm{Bcl}-2$ and $\mathrm{Bcl}-\mathrm{xL}$ expression, signal transducer and activator of transcription-5 (STAT-5) (38, 39), is activated by phosphorylation of the Tyr 694 residue (40). STAT-5 was found to be phosphorylated on Tyr 694 (pSTAT-5) in T cells maintained in IL-2, and withdrawal of IL-2 led to loss of both STAT- 5 protein and PSTAT-5 within 1 hour in WT T cells (Figure 7B). However, WT T cells treated with MnTBAP as well as iNOS ${ }^{-/-} \mathrm{T}$ cells subjected to IL-2 withdrawal showed the persistence of higher levels of both total STAT-5 and pSTAT-5 (Figure 7B).

Primary $T$ cell responses are not enhanced either by the absence of $i N O S$ or by peroxynitrite scavenging. The data shown so far demonstrate the enhanced persistence of primed T cells in the absence of iNOS or peroxynitrite, associated with enhanced resistance of $\mathrm{T}$ cells to death by neglect. However, before relating the two findings causally, it was necessary to examine whether primary $T$ cell activation was enhanced in the absence of iNOS or peroxynitrite, resulting in the generation of greater numbers of primed T cells, which could provide a mechanism for enhanced persistence of $\mathrm{T}$ cell memory independent of effects on $\mathrm{T}$ cell death pathways. To address this, splenic cells from $\mathrm{iNOS}^{-/-}$or WT mice were stimulated with titrated concentrations of anti-CD3 $\mathrm{mAb}$, and the cultures were pulsed with tritiated thymidine at various subsequent time points. No differences were observed between the proliferation profiles thus obtained (Figure 8, D-F). Similarly, the addition of MnTBAP to such cultures of WT cells also did not alter the proliferation profiles (Figure $8, \mathrm{~A}-\mathrm{C}$ ). The relevance of iNOS and peroxynitrite of APC origin was also tested by irradiated allo-APCs from $\mathrm{BALB} / \mathrm{c}$ mice for primary $\mathrm{T}$ cell stimulation in vitro, and once again, no differences were induced by the absence of $\mathrm{iNOS}$ in $\mathrm{T}$ cells (Figure 8, J-L), or by the presence of MnTBAP (Figure 8, G-I).

We further examined whether the absence of iNOS/peroxynitrite had any effects on the early immune responses in vivo to immunization. WT or iNOS ${ }^{-/-}$mice were immunized subcutane- ously with maleyl-OVA in CFA, with one group of WT mice being treated with MnTBAP as above, and T cell-proliferative responses recalled by antigen in culture were estimated 1 week later. Once again, neither MnTBAP treatment nor the absence of iNOS led to any increase in the magnitude of immune responses measured early during immunization (Figure $8 \mathrm{M}$ ), in contrast to the differences revealed at later time points.

Inbibition of nitric oxide pathway during buman T cell priming in vitro enhances T cell memory and blocks T cell TSWD. Since these findings clearly have implications relevant to vaccine-design strategies, we also extended them to human T cells. We used the system of alloMHC immunization in vitro with cells from HLA-mismatched healthy blood donors that we reported in previous work. Responder PBMCs were immunized in vitro by priming in culture with lightly paraformaldehyde-fixed PBMCs from HLA-mismatched individuals, and the efficiency of $\mathrm{T}$ cell priming was detected as described earlier. When MnTBAP was added to these priming cultures, it clearly enhanced the secondary response (Figure 9A). While inhibitors of nitric oxide synthase such as AG or L-NMMA during priming also enhanced the secondary responses generated (Figure 9, B and C), a cell-permeable form of glutathione, glutathionemonoethyl ester (GSH-mee), did not do so (Figure 9D), indicating that nitric oxide generation is likely to be more critical than ROS. The event affected by MnTBAP was not any early signal during $\mathrm{T}$ cell activation but a fairly late one during priming in vitro, since the addition of MnTBAP during the last 48 hours of a 4-day priming culture was sufficient to give its full effect on the enhancement of secondary responsiveness (Figure 9E).

To confirm the effect of MnTBAP on PAD of human T cells, PBMCs were activated with anti-human CD3 mAb and IL-2, and the activated T cells were kept in medium devoid of IL-2 for induction of TSWD, with or without AG, L-NMMA, or MnTBAP. Death in CD4 and CD8 cells was detected as described earlier. The presence of AG, L-NMMA, or MnTBAP substantially reduced the proportion of apoptotic cells in both CD4 and CD8 compartments (Figure 9, F-H).

We also tested the effects of the blockade of the CD95-CD95L interactions, or of caspase inhibition, in these allo-priming cultures. Neither the addition of an anti-CD95L mAb known to block CD95-CD95L interactions, nor the addition of a pan-caspase inhibitor, ZVAD-fluoromethylketone (ZVAD-fmk), during priming led to any enhancement of secondary $\mathrm{T}$ cell-proliferative responses (Figure 9, I and J). However, the addition of these agents during the stimulation of previously primed $\mathrm{T}$ cells led to enhancement of the proliferative responses (Figure 9K), indicating that these agents were nontoxic and effective.

\section{Discussion}

Our data implicate iNOS in $\mathrm{T}$ cells in the regulation of postactivation death by neglect and of the size of both CD4 and CD8 $\mathrm{T}$ cell memory pools in both human and mouse systems. The increased frequencies of surviving CD4 T cells capable of mediating a recall proliferative response (Figure 1), and of both CD4 and CD8 $\mathrm{T}$ cells capable of making IFN- $\gamma$ rapidly in iNOS $-/-$ mice (Figure 2), demonstrate the enhancement of the surviving T cell memory pool in these mice. Further, the increase in frequencies of both CD4 and CD8 effector/memory T cells, based on their CD44hi or CD62 $\mathrm{L}^{\text {lo }}$ phenotype in iNOS $/$ - mice (Figure 3), is also consistent with the possibility that memory $\mathrm{T}$ cells generally persist more efficiently in these mice even after environmental antigen exposure. 

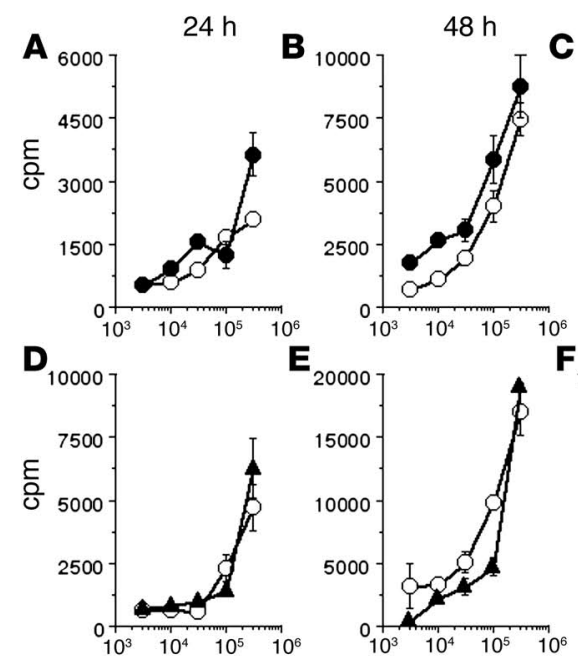

Allo-APCs/well
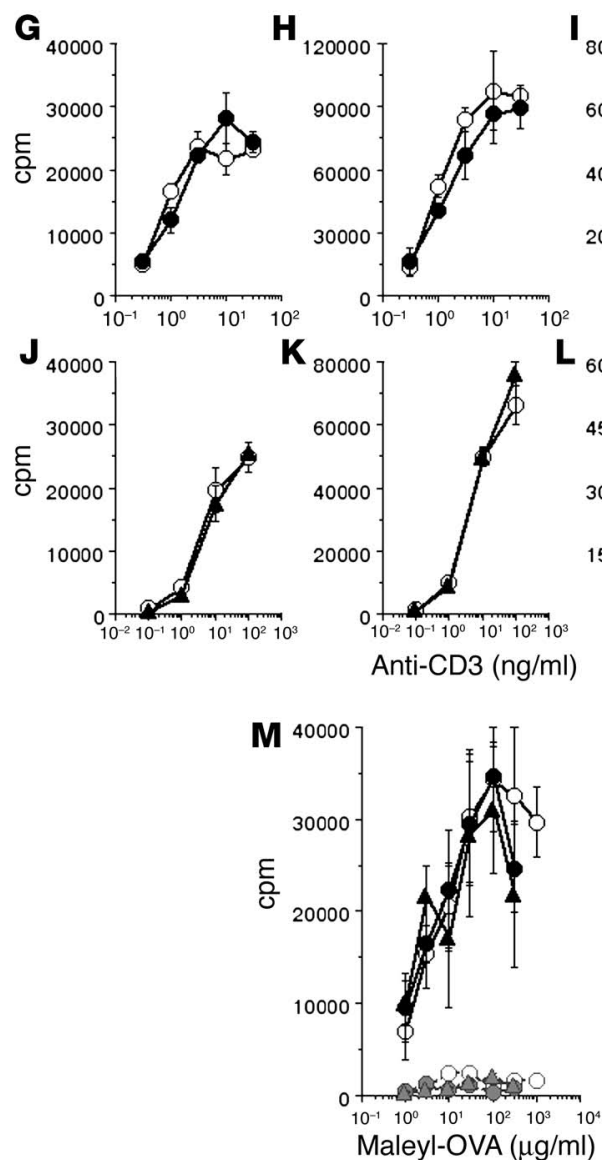

It is quite possible that iNOS expression in APCs, rather than T cells, is responsible for modulation of a variety of APC functions. In fact, the possibility that iNOS or peroxynitrite in APCs is relevant to the results seen cannot be formally and directly ruled out in approaches using MnTBAP or iNOS inhibitors in vivo (Figure 6). However, we also see enhancement of memory CD4 and CD8 $\mathrm{T}$ cell frequencies in these mice even when allo-APCs from WT $\mathrm{BALB} / \mathrm{c}$ mice, themselves capable of expressing iNOS, are used for immunization (Figures 4 and 6), which shows that iNOS of

\section{Figure 8}

Primary $T$ cell responses are not enhanced either by the absence of iNOS or by peroxynitrite scavenging. (A-F) Mouse splenic cells were stimulated with titrating concentrations of irradiated BALB/c splenic cells as allo-APCs, and T cell proliferation was assayed at the times indicated (WT cells, open circles; WT cells plus $100 \mu \mathrm{M}$ MnTBAP, filled circles; iNOS ${ }^{-/-}$cells, filled triangles). (G-L) Mouse splenic cells were stimulated with titrating concentrations of anti-CD3 mAb, and $\mathrm{T}$ cell proliferation was assayed at the times indicated (WT cells, open circles; WT cells plus $100 \mu \mathrm{M}$ MnTBAP, filled circles; iNOS ${ }^{-/}$cells, filled triangles). (M) Groups of mice were immunized with maleyl-OVA and treated with saline or MnTBAP daily from day -2 to day +5 of immunization, and the proliferative memory response was measured after 1 week (WT nonimmunized, open circles, dotted line; WT immunized, open circles, solid line; WT nonimmunized and MnTBAP-treated, filled circles, dotted line; WT immunized and MnTBAP-treated, filled circles, solid line; iNOS ${ }^{--}$nonimmunized, filled triangles, dotted line; iNOS ${ }^{-/}$ immunized, filled triangles, solid line).

APC origin is not critical for the observed control of T cell memory. We have confirmed these observations by transferring WT or iNOS $^{-/}$splenic cells to Thy-1-congenic recipients, in which donor Thy-1.2 cells can mount immune responses in an $\mathrm{iNOS}^{+/+}$microenvironment and can be phenotypically identified to measure the persistence of immune memory in recipient mice. By 40 days after immunization, $\mathrm{iNOS}^{-/-} \mathrm{T}$ cells show greater persistence of memory than WT cells do (Figure 4), supporting the interpretation that iNOS in T cells is a determinant of T cell memory.

While a number of possible mechanisms may account for the effect of the absence of iNOS on T cell memory, our data provide a major correlation with the role of iNOS in death by neglect (TSWD) of T cells after activation. Activated WT T cells express iNOS, while $\mathrm{iNOS}^{-/} \mathrm{T}$ cells express higher levels of the antiapoptotic protein $\mathrm{Bcl}-$ $\mathrm{xL}$ than WT T cells do, and there is less apoptotic TSWD in activated CD4 and CD8 $\mathrm{T}$ cells from $\mathrm{iNOS}^{-/-}$mice than in cells from WT mice (Figure 5); these results indicate a connection among iNOS, Bcl-xL, TSWD, and immune memory. On the other hand, T cells of B6.lpr mice, which, unlike iNOS ${ }^{-/}$T cells, show resistance to AICD but not TSWD (Figure 5), are no better at generating immune memory than WT T cells are (Figure 6), which indicates that TSWD is more crucial than AICD for immune memory. The persistence of immune memory in the absence of iNOS/peroxynitrite is not due to any enhancement of primary $\mathrm{T}$ cell responses under these conditions, since primary responses are unaltered (Figure 8). The findings are not related to any developmental alteration in the $\mathrm{T}$ cells of iNOS-/- mice, since inhibition of the iNOS-peroxynitrite pathway in normal $\mathrm{T}$ cells from both mice and humans leads to enhancement of the secondary $\mathrm{T}$ cell commitment upon immunization in vitro, as well as to protection from postactivation TSWD (Figures 6 and 9). Since cell-permeable glutathione cannot mimic these effects, but inhibitors of the enzymatic activity of iNOS can (Figures 6 and 9), and since MnTBAP mimics them in WT but not in $\mathrm{iNOS}^{-/-} \mathrm{T}$ cells (Figure 6), the iNOS-nitric oxide-peroxynitrite pathway in T cells appears to be a major rate-limiting factor for the cell-fate decision of death versus memory. Peroxynitrite is a highly toxic agent and induces apoptosis via mitochondria $(16,18,23)$. This death pathway relevant to the memory decision is unaffected not only by the absence of the death receptor CD95, but also by the inhibition of caspases (Figures 6 and 9), suggesting that caspase-independent events $(20,24)$ may be crucial for the effector stages of this apoptotic TSWD pathway downstream of mitochondrial damage. 

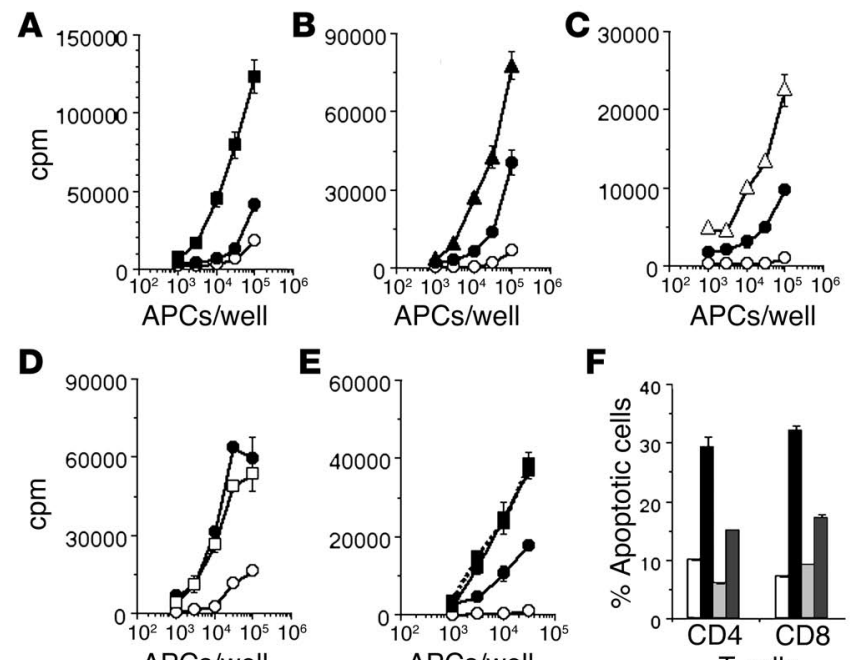

E

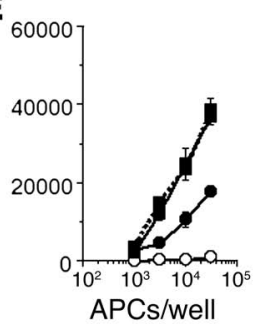

$\mathbf{F}$
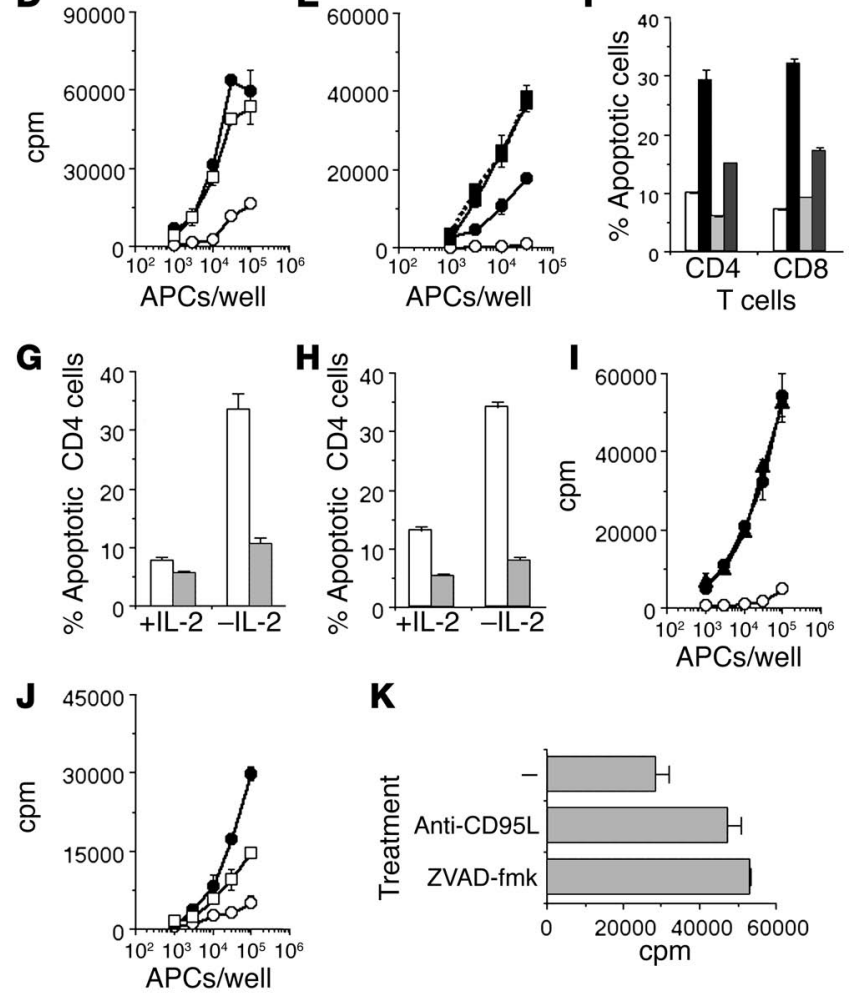

$\mathbf{K}$

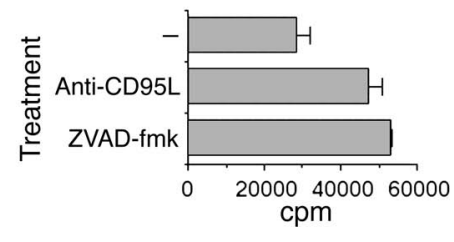

The two major triggers implicated in the choices mature $\mathrm{T}$ cells make between death and survival are $\mathrm{T}$ cell receptor-mediated (TCR-mediated) activation and trophic signal withdrawal $(6,12,17)$. Downstream death pathways in the former category are thought to be death receptor-mediated $(6,13)$, while those in the latter appear to involve mitochondria $(15,16)$. Since immune responses are a consequence of TCR-mediated activation, death receptor-mediated pathways could be expected to be prominent in them too. However, TCR- and death receptor-mediated pathways need extensive and repeated TCR engagement, such as that provided by autoantigens, to be effective (20), and it is somewhat doubtful whether this is available during immune responses, particularly during immunization by nonreplicating immunogens. There are observations suggesting that, while immune responses to infectious agents may be modulated by death receptor-mediated signals $(42,43)$, immune memory in response to immunization with proteins in adjuvants is unaffected by death receptors (44) but is enhanced if $T$ cells overexpress antiapoptotic proteins of the Bcl-2 family (45), which inhibit mitochondria-mediated death rather than death receptor-mediated apoptosis $(23,24)$.

Our data take this model a major step further by implicating the induction of iNOS in $\mathrm{T}$ cells in the postactivation death by neglect that helps determine the extent of immune memory generated,

\section{Figure 9}

Inhibition of nitric oxide pathway enhances human T cell memory and blocks PAD. (A-E) Human PBMCs were incubated alone (open circles) or primed with lightly fixed HLA-mismatched stimulator PBMCs in vitro without (filled circles) or with MnTBAP (filled squares, A), AG (filled triangles, B), L-NMMA (open triangles, C), or GSH-mee (open squares, D), or with MnTBAP during 48-96 hours of the priming period (filled squares, dotted line, E), and restimulated with stimulator PBMCs. (F) TSWD in CD4 or CD8 human T cell blasts put in culture with IL-2 (white bars), or without IL-2 in medium alone (black bars) or with AG (light gray bars) or L-NMMA (dark gray bars) for 24 hours. Frequencies of apoptotic cells are shown as mean \pm SE of triplicate cultures. ( $\mathbf{G}$ and $\mathbf{H}$ ) TSWD in T cell blasts put in culture with or without IL-2 in the absence (white bars) or presence (gray bars) of MnTBAP for 12 hours. Frequencies of apoptotic CD4 (G) or CD8 (H) cells are shown as mean \pm SE of triplicate cultures. (I and $\mathbf{J}$ ) Human PBMCs were incubated alone (open circles) or primed with HLA-mismatched stimulator PBMCs in vitro without (filled circles) or with anti-CD95L (filled triangles, I) or ZVAD-fmk (open squares, J), and restimulated with stimulator PBMCs. (K) Human PBMCs, allo-primed in vitro, were restimulated with allo-stimulator PBMCs in the absence $(-)$ or presence of agents shown.

although iNOS may be playing additional roles in T cell memory by other mechanisms as well. Based on our data, it is likely that this effect is mediated, at least in part, by the role of iNOS activity in reducing levels of antiapoptotic members of the Bcl-2 family, such as Bcl-2 and Bcl-xL (Figure 7), that are required for apoptotic death. In T cells undergoing death by neglect, absence of iNOS activity also mitigates the reduction of both the total and the Tyr-694-phosphorylated form of the signaling intermediate STAT-5 (Figure 7), indicating a possible point of intervention. Our findings suggest that iNOS is globally relevant to CD4 as well as CD8 T cell memory in both mouse and human systems. Our observations are also consistent with data showing that free radicals are involved in the maintenance of immune memory $(23,24)$, and they make it possible to speculate that iNOS-mediated signals are important for homeostatic $\mathrm{T}$ cell maintenance. In fact, we have observed that resting iNOS ${ }^{-/} \mathrm{T}$ cells are also relatively resistant to death by neglect (46), and the increased numbers of naive $\mathrm{T}$ cells that we observed in $\mathrm{iNOS}^{-/}$- lymph nodes are consistent with such a homeostatic role for iNOS.

If $\mathrm{T}$ cell death by neglect, a consequence of the withdrawal of trophic signals due to antigen clearance, is the only death pathway operative in normal immune responses, $\mathrm{T}$ cell memory generation may be linear, in that all responding $\mathrm{T}$ cells are activated, enter this TSWD pathway, and, if they survive, become memory cells. On the other hand, at least in some immune responses, effector and memory T cell differentiation may still diverge at some point during immune responses, with effector cells undergoing death receptor-mediated AICD, and memory cells undergoing this peroxynitrite-mediated mitochondrial TSWD. It is possible that secondary immune $T$ cells may in fact die upon challenge through a death receptor-mediated caspase-dependent pathway, since the proliferation of primed T cells is enhanced by blockade of CD95L and of caspases (Figure 9).

The death pathway involved here is probably triggered after initial $\mathrm{T}$ cell activation, since late addition of MnTBAP during $\mathrm{T}$ cell priming in vitro is sufficient to enhance secondary $\mathrm{T}$ cell responses (Figure 9). However, this death decision is likely to be made in the early days of an immune response induced in vivo, since transient treatment with MnTBAP or AG in vivo is sufficient to enhance the persistence of $\mathrm{T}$ cell responses (Figure 6). We have previously report- 
ed that an increase in the duration of the cAMP-protein kinase A signaling pathway by phosphodiesterase inhibitors such as the commonly used drug pentoxifylline also prevents death of $\mathrm{T}$ cells after activation and enhances $T$ cell memory $(32,33)$. Preliminary data indicate that pentoxifylline enhances immune memory by inhibiting the RNI-mediated TSWD pathway we identify here (data not shown), reinforcing the probability that this death pathway is crucial in the memory decision of responding $\mathrm{T}$ cells, and that modulation of elements in this pathway can enhance immune memory. Such pharmacological immune adjuvants that specifically enhance $T$ cell memory without inducing inflammation would be useful in vaccine design.

\section{Methods}

All experiments using mouse and human systems were done with the approval of the appropriate institutional ethical supervisory committees.

Mice and immunization. All mouse strains used were from The Jackson Laboratory (Bar Harbor, Maine, USA) and maintained in the Small Animal Facility of the National Institute of Immunology. Mice 8-12 weeks of age were used routinely for experiments. WT C57BL/ 6 or iNOS $^{-/-}$mice were immunized subcutaneously with 100 $\mu \mathrm{g}$ maleyl-OVA or a combination of $10 \mu \mathrm{g}$ each of SIINFEKL (OVA1) and ISQAVHAAHAEINEAGR (OVA2) peptide in CFA; with $1 \mathrm{mg}$ OVA or $300 \mu \mathrm{g}$ of maleyl-OVA on alum; or with $100 \mu \mathrm{g}$ maleyl-OVA in CFA per mouse as indicated. Mice were given saline or MnTBAP (60 $\mu \mathrm{g} /$ mouse intraperitoneally; Calbiochem-Novabiochem Corp., La Jolla, California, USA) or AG (2 mg/mouse intraperitoneally; Sigma-Aldrich, St. Louis, Missouri, USA) daily from days -2 to +5 of immunization where indicated. For allo-immunization, WT or iNOS $^{-/-}\left(\mathrm{H}-2^{\mathrm{b}}\right)$ mice received $30 \times 10^{6} \gamma$-irradiated (10 Gy with $\mathrm{Co}^{60}$ source) spleen cells from $\mathrm{BALB} / \mathrm{c}\left(\mathrm{H}-2^{\mathrm{d}}\right)$ mice.

B6.PL-Thy $1^{a} /$ Cy congenic mice carrying the Thy-1.1 allotype were lightly $\gamma$-irradiated (3 Gy) and were intravenously given $2 \times 10^{7}$ B6.PL-Thy $1^{a} /$ Cy splenic cells together with $2 \times 10^{7}$ Thy- 1.2 splenic cells from either WT or iNOS-/- mice, and the recipients were immunized 24 hours later.

$T$ cell activation assays in vitro. Either splenic cells or purified $\mathrm{T}$ cells from WT, iNOS ${ }^{-/}$, or B6.lpr mice were allo-primed with $\gamma$-irradiated (10 Gy) BALB/c spleen cells for $60-72$ hours $(2: 1$ ratio) in the presence or absence of $100 \mu \mathrm{M}$ MnTBAP or 100 $\mu \mathrm{g} / \mathrm{ml} \mathrm{AG}$, harvested, and restimulated with irradiated BALB/c spleen cells. The response of $\mathrm{T}$ cells was read out as ${ }^{3} \mathrm{H}$-thymidine incorporation or by flow cytometry.

For allo-priming of human T cells in vitro, responder PBMCs were primed with irradiated (30 Gy) and paraformaldehyde-fixed stimulators (33) in the presence or absence of MnTBAP $(100 \mu \mathrm{M})$, AG $(100 \mu \mathrm{g} / \mathrm{ml})$, L-NMMA $(300 \mu \mathrm{M}$; Calbiochem-Novabiochem Corp.), GSH-mee (100 $\mu \mathrm{M}$; Calbiochem-Novabiochem Corp.), anti-CD95L $(1 \mu \mathrm{g} / \mathrm{ml}$; BD Pharmingen, San Diego, California, USA), or ZVAD-fmk (30 $\mu \mathrm{M}$; Promega Corp., Madison, Wisconsin, USA) for 96 hours, harvested, and restimulated with stimulator PBMCs. Where specifically mentioned, anti-CD95L and ZVADfmk were added only during the secondary response. Proliferation was measured by ${ }^{3} \mathrm{H}$-thymidine incorporation.

For cell-death assays, human PBMCs or mouse spleen cells were stimulated with appropriate mAb's (OKT3 or C363.29B, respectively) for 48 hours and with IL-2 $(10 \mathrm{U} / \mathrm{ml})$ for a further 48 hours, and viable cells were harvested. These $\mathrm{T}$ cell blasts were cultured in the presence or absence of $5 \mathrm{U} / \mathrm{ml}$ of IL-2 (Roche Diagnostics $\mathrm{GmbH}$, Mannheim, Germany) for induction of TSWD, or were cultured in IL-2 with or without plate-coated anti-CD3 for induction of AICD, with or without $100 \mu \mathrm{M}$ MnTBAP, $100 \mu \mathrm{g} / \mathrm{ml} \mathrm{AG}$, or $300 \mu \mathrm{M}$ L-NMMA. Cells were stained at various intervals from 0 to 48 hours with appropriate labeled anti-CD4 or anti-CD8 mAb's (BD Pharmingen), and Hoechst 33342 (5 $\mu \mathrm{g} / \mathrm{ml}$; Molecular Probes Inc., Eugene, Oregon, USA) was added for visualization of nuclear morphology by fluorescent microscopy (TE2000-U; Nikon Corp., Tokyo, Japan). Between 150 and 200 cells were counted, and results are expressed as mean \pm SE of triplicate cultures. Culture supernatants from cells undergoing death by neglect were also collected and assayed for levels of IL-2 generated, using commercial ELISA kits (BD Pharmingen).

Tcell proliferation assays and limiting-dilution analysis. Splenic or lymph node cells from immunized mice were plated in the presence or absence of titrated concentrations of antigen, and wells were pulsed with tritiated thymidine 72-96 hours later. Data are shown as mean $\mathrm{cpm} \pm \mathrm{SE}$. For analysis of clonal frequency of antigen-specific T cells, splenic cells from immunized mice were plated in titrating numbers in the presence or absence of antigen and irradiated syngeneic splenic cells. Wells showing a response at least threefold above background were scored positive. Based on frequencies of negative wells in each group, the clonal frequency was calculated as reported earlier (41). Burst size was calculated taking positive wells at clonal frequency in each group into account. Data are shown as mean cpm \pm SE.

Flow cytometry. Cells were isolated from inguinal lymph nodes and stained for CD4/CD8 and CD44/CD62L in two-color flow cytometric analyses. For visualization of cytokine production by $\mathrm{T}$ cells, cells were permeabilized and stained in a three-color analysis for CD4/CD8, CD44/Thy-1.2, and intracellular IFN- $\gamma$ (BD Pharmingen) 24-96 hours after in vitro stimulation of lymph node cells. Monensin $(5 \mu \mathrm{M})$ was added for the last 6 hours of culture, sometimes along with phorbol myristate acetate $(10 \mathrm{ng} / \mathrm{ml})$ and ionomycin $(100 \mathrm{ng} / \mathrm{ml})$, and about 50,000 gated CD4 or CD8 cells were counted for the analyses. For enumerating cell divisions of allo-responding cells, responder lymph node cells were labeled with CFSE (10 $\mu \mathrm{M}$; Molecular Probes Inc.), stimulated with irradiated BALB/c APCs, harvested after 96 hours, and stained in a threecolor analysis for CD4, CD8, and MHC class I with the $\mathrm{H}-2^{\mathrm{b}}$ specific $\mathrm{mAb}$. Stimulator APCs did not stain with Y-3 and were excluded to analyze responder CD4 or CD8 cells for the proportions undergoing CFSE dilution. Either BD LSR (BD Biosciences, San Jose, California, USA) or Elite ESP (Beckman Coulter Inc., Fullerton, California, USA) flow cytometers were used for data acquisition, and analysis was done using FlowJo software (Tree Star Inc., San Carlos, California, USA).

Western blot analysis. Whole-cell lysates were prepared from activated $\mathrm{T}$ cells from WT or iNOS $^{-/-}$mice as described previously (31), electrophoresed on SDS-PAGE, and transferred onto nitrocellulose membranes (Amersham Biosciences AB, Uppsala, Sweden). Membranes were probed with anti-iNOS antibody (BD Pharmingen). Activated T cells from WT or iNOS ${ }^{-/}$mice were also put into culture with or without IL-2 or MnTBAP $(100 \mu \mathrm{M})$ as described above for 1 hour or 12 hours as indicated, and whole-cell lysates were prepared. The lysates were subjected to SDS-PAGE and Western blotting with antibodies against Bcl-2, Bcl-xL, p38MAPK, or actin, or with antibodies specific for either STAT-5 or the Tyr 694-phosphorylated form of STAT-5 (pSTAT-5) (Cell Signaling Technology Inc., Beverly, Massachusetts, USA). Antibody binding was detected by enhanced chemiluminescence (Pierce Biotechnology Inc., Rockford, Illinois, USA). 


\section{Acknowledgments}

This work was supported in part by grants from the Department of Science and Technology and the Department of Biotechnology, Government of India (to A. George, S. Rath, and V. Bal); the Indian Council of Medical Research (to S. Rath); the Wellcome Trust (to V. Bal); the Indo-US Vaccine Action Program (to J.M. Durdik, S. Rath, V. Bal, and A. George); and the NIH (R15 AG021896, to J.M. Durdik). The National Institute of Immunology is supported by the Department of Biotechnology, Government of India.

Received for publication October 7, 2003, and accepted in revised form April 14, 2004.

1. Blattman, J.N., et al. 2002. Estimating the precursor frequency of naive antigen-specific CD8 T cells. J. Exp. Med. 195:657-664.

2. Murali-Krishna, K., et al. 1998. Counting antigenspecific CD8 T cells: a reevaluation of bystander activation during viral infection. Immunity. 8:177-187.

3. Maini, M.K., Gudgeon, N., Wedderburn, L.R., Rickinson, A.B., and Beverley, P.C. 2000. Clonal expansions in acute EBV infection are detectable in the CD8 and not the CD4 subset and persist with a variable CD45 phenotype. J. Immunol. 165:5729-5737.

4. Murphy, K.M., and Reiner, S.L. 2002. The lineage decisions of helper T cells. Nat. Rev. Immunol. 2:933-944.

5. Hu, H., et al. 2001. CD4(+) T cell effectors can become memory cells with high efficiency and without further division. Nat. Immunol. 2:705-710.

6. van Parijs, L., Peterson, D.A., and Abbas, A.K. 1998 The Fas/Fas ligand pathway and Bcl-2 regulate $\mathrm{T}$ cell responses to model self and foreign antigens. Immunity. 8:265-274.

7. Geginat, J., Sallusto, F., and Lanzavecchia, A. 2001 Cytokine-driven proliferation and differentiation of human naive, central memory, and effector memory CD4(+) T cells. J. Exp. Med. 194:1711-1719.

8. Sallusto, F., Lenig, D., Forster, R., Lipp, M., and Lanzavecchia, A. 1999. Two subsets of memory T lymphocytes with distinct homing potentials and effector functions. Nature. 401:708-712.

9. Wherry, E.J., et al. 2003. Lineage relationship and protective immunity of memory CD8 T cell subsets. Nat. Immunol. 4:225-234.

10. Opferman, J.T., Ober, B.T., and Ashton-Rickardt, P.G. 1999. Linear differentiation of cytotoxic effectors into memory $\mathrm{T}$ lymphocytes. Science. 283:1745-1748.

11. Farber, D.L. 1998. Differential TCR signaling and the generation of memory T cells. J. Immunol. 160:535-539.

12. Hildeman, D.A., Zhu, Y., Mitchell, T.C., Kappler, J., and Marrack, P. 2002. Molecular mechanisms of activated $\mathrm{T}$ cell death in vivo. Curr. Opin. Immunol. 14:354-359.

13. Noble, A., Pestano, G.A., and Cantor, H. 1998. Suppression of immune responses by CD8 cells. I. Superantigen-activated CD8 cells induce unidirectional Fas-mediated apoptosis of antigen-activated CD4 cells. J. Immunol. 160:559-565.

14. White, D.W., and Harty, J.T. 1998. Perforin-deficient CD8+ T cells provide immunity to Listeria monocytogenes by a mechanism that is independent of CD95 and IFN-gamma but requires TNF-alpha. J. Immunol. 160:898-905.

15. Devadas, S., Zaritskaya, L., Rhee, S.G., Oberley, L., and Williams, M.S. 2002. Discrete generation of superoxide and hydrogen peroxide by $\mathrm{T}$ cell receptor stimulation: selective regulation of mitogen-activated protein kinase activation and fas ligand expression. J. Exp. Med. 195:59-70.

16. Castedo, M., et al. 1995. Mitochondrial perturbations define lymphocytes undergoing apoptotic depletion

Address correspondence to: Vineeta Bal, National Institute of Immunology, Aruna Asaf Ali Road, New Delhi 110 067, India. Phone: 91-11-26703695; Fax: 91-11-26162125; E-mail: vineeta@nii.res.in. Or to: Jeannine M. Durdik, Department of Biological Sciences, University of Arkansas, Fayetteville, Arkansas 72701, USA. Phone: (479) 575-8375; Fax: (479) 575-4010; E-mail: jdurdik@uark.edu.

Monika Vig, Smita Srivastava, and Usha Kandpal contributed equally to this work.

Anna George, Vineeta Bal, Jeannine M. Durdik, and Satyajit Rath contributed equally to this work as senior investigators.

in vivo. Eur. J. Immunol. 25:3277-3284

17. Huleatt, J.W., Cresswell, J., Bottomly, K., and Crispe, I.N. 2003. P27kip1 regulates the cell cycle arrest and survival of activated $\mathrm{T}$ lymphocytes in response to interleukin-2 withdrawal. Immunology. 108:493-501.

18. Ferraro-Peyret, C., Quemeneur, L., Flacher, M., Revillard, J.P., and Genestier, L. 2002. Caspaseindependent phosphatidylserine exposure during apoptosis of primary T lymphocytes. J. Immunol. 169:4805-4810.

19. Hildeman, D.A., et al. 1999. Reactive oxygen species regulate activation-induced $\mathrm{T}$ cell apoptosis. Immunity. 10:735-744.

20. Zhang, J., Bardos, T., Mikecz, K., Finnegan, A., and Glant, T.T. 2001. Impaired Fas signaling pathway is involved in defective $T$ cell apoptosis in autoimmune murine arthritis. J. Immunol. 166:4981-4986.

21. Davila, E., Velez, M.G., Heppelmann, C.J., and Celis, E. 2002. Creating space: an antigen-independent, CpG-induced peripheral expansion of naive and memory T lymphocytes in a full T-cell compartment. Blood. 100:2537-2545.

22. Schirmer, M., Vallejo, A.N., Weyand, C.M., and Goronzy, J.J. 1998. Resistance to apoptosis and elevated expression of Bcl-2 in clonally expanded CD4+CD28- $\mathrm{T}$ cells from rheumatoid arthritis patients. J. Immunol. 161:1018-1025.

23. Hildeman, D.A., Mitchell, T., Kappler, J., and Marrack, P. 2003. T cell apoptosis and reactive oxygen species. J. Clin. Invest. 111:575-581. doi:10.1172/ JCI200318007.

24. Bidere, N., and Senik, A. 2001. Caspase-independent apoptotic pathways in $\mathrm{T}$ lymphocytes: a minireview. Apoptosis. 6:371-375.

25. Moulian, N., Truffault, F., Gaudry-Talarmain, Y.M., Serraf, A., and Berrih-Aknin, S. 2001. In vivo and in vitro apoptosis of human thymocytes are associated with nitrotyrosine formation. Blood. 97:3521-3530.

26. MacMicking, J.D., et al. 1995. Altered responses to bacterial infection and endotoxic shock in mice lacking inducible nitric oxide synthase. Cell. 91:641-650.

27. Beltran, B., et al. 2002. Inhibition of mitochondrial respiration by endogenous nitric oxide: a critical step in Fas signaling. Proc. Natl. Acad. Sci. U. S. A. 99:8892-8897.

28. Shastri, N., and Gonzalez, F. 1993. Endogenous generation and presentation of the ovalbumin peptide/ Kb complex to T cells. J. Immunol. 150:2724-2736.

29. Robertson, J.M., Jensen, P.E., and Evavold B.D. 2000. DO11.10 and OT-II T cells recognize a Cterminal ovalbumin 323-339 epitope. J. Immunol. 164:4706-4712.

30. Bansal, P., et al. 1999. MHC class I-restricted presentation of maleylated protein binding to scavenger receptors. J. Immunol. 162:4430-4437.

31. Sade, H., and Sarin, A. 2003. IL-7 inhibits dexamethasone-induced apoptosis via Akt/PKB in mature, peripheral T cells. Eur. J. Immunol. 33:913-919.

32. Suresh, R., et al. 2002. Pentoxifylline functions as an adjuvant in vivo to enhance $T$ cell immune responses by inhibiting activation-induced death. J. Immunol. 169:4262-4272

33. Vig, M., et al. 2002. Commitment of activated T cells to secondary responsiveness is enhanced by signals mediated by cAMP-dependent protein kinase A-I. Mol. Pharmacol. 62:1471-1481.

34. Pfeiffer, S., Lass, A., Schmidt, K., and Mayer, B. 2001. Protein tyrosine nitration in mouse peritoneal macrophages activated in vitro and in vivo: evidence against an essential role of peroxynitrite. FASEB J. 15:2355-2364.

35. Melov, S., et al. 1998. A novel neurological phenotype in mice lacking mitochondrial manganese superoxide dismutase. Nat. Genet. 18:159-163.

36. Kim, J.Y., et al. 2003. Inducible nitric oxide synthase inhibitors prolonged the survival of skin xenografts through selective down-regulation of pro-inflammatory cytokine and CC-chemokine expressions. Transpl. Immunol. 12:63-72.

37. Mukhopadhyay, S., George, A., Bal, V., Ravindran, B., and Rath, S. 1999. Bruton's tyrosine kinase deficiency in macrophages inhibits nitric oxide generation leading to enhancement of IL-12 induction. J. Immunol. 163:1786-1792.

38. Lord, J.D., McIntosh, B.C., Greenberg, P.D., and Nelson, B.H. 2000. The IL-2 receptor promotes lymphocyte proliferation and induction of the c-myc, bcl-2, and $\mathrm{bcl}-\mathrm{x}$ genes through the trans-activation domain of Stat5. J. Immunol. 164:2533-2541.

39. Socolovsky, M., Fallon, A.E., Wang, S., Brugnara, C., and Lodish, H.F. 1999. Fetal anemia and apoptosis of red cell progenitors in Stat5a-/-5b-/- mice: a direct role for Stat 5 in $\mathrm{Bcl}-\mathrm{X}(\mathrm{L})$ induction. Cell. 98:181-191.

40. Gouilleux, F., Wakao, H., Mundt, M., and Groner, B. 1994. Prolactin induces phosphorylation of Tyr694 of Stat5 (MGF), a prerequisite for DNA binding and induction of transcription. EMBO J. 13:4361-4369.

41. Gupta, M., et al. 1999. Presence of pentoxifylline during $\mathrm{T}$ cell priming increases clonal frequencies in secondary proliferative responses and inhibits apoptosis. J. Immunol. 162:689-695.

42. Vazquez-Torres, A., Fantuzzi, G., Edwards, C.K., 3rd, Dinarello, C.A., and Fang, F.C. 2001. Defective localization of the NADPH phagocyte oxidase to Salmonella-containing phagosomes in tumor necrosis factor p55 receptor-deficient macrophages. Proc. Natl. Acad. Sci. U. S. A. 98:2561-2565.

43. Pfeffer, K., et al. 1993. Mice deficient for the $55 \mathrm{kd}$ tumor necrosis factor receptor are resistant to endotoxic shock, yet succumb to L. monocytogenes infection. Cell. 73:457-467.

44. Bouzahzah, F., Jung, S., and Craft, J. 2003. CD4+ T cells from lupus-prone mice avoid antigen-specific tolerance induction in vivo. J. Immunol. 170:741-748.

45. Strasser, A., Harris, A.W., and Cory, S. 1991. bcl-2 transgene inhibits $\mathrm{T}$ cell death and perturbs thymic self-censorship. Cell. 67:889-899.

46. Sade, H., and Sarin, A. 2004. Reactive oxygen species regulate quiescent $\mathrm{T}$-cell apoptosis via the BH3-only proapoptotic protein BIM. Cell Death Differ. 11:416-423. 